\title{
A Parisian spring: the debate on language localization at the Imperial Academy of Medicine, Paris, April 4-June 13, 1865
}

\author{
Richard Leblanc, MSc, MD, FRCSC \\ Department of Neurology and Neurosurgery, Montreal Neurological Institute and McGill University, Montreal, Quebec, Canada
}

The localization of articulate language (speech) to the posterior third of the third left frontal convolution-Broca's areadid not occur to Broca as he reported the case of his first aphasic patient in 1861. Initially Broca localized articulate language to both frontal lobes, a position that he maintained for 4 years after publishing his first case. In the interval, the Academy of Medicine in Paris had received a copy of a paper authored in 1836 by Marc Dax, in which Dax claimed that the ability to speak resides within the left hemisphere alone. The Academy of Medicine convened in the spring of 1865 to adjudicate the issue. All of the distinguished speakers argued against Dax's contention by citing the prevailing paradigm, that bilaterally symmetrical organs, such as the eyes and ears, and the hemispheres of the brain, must perform the same function. The lone dissenting voice was that of Jules Baillarger, the discoverer of the laminar organization of the cerebral cortex, whose argument in favor of what he called "Dax's law" was so lucid that it carried the day. During his address to the Academy, Baillarger not only supported left-hemisphere dominance for speech, but for the first time described two forms of aphasia, fluent and nonfluent, now referred to as Wernicke's and Broca's aphasias, respectively, as well as the ability of aphasics to speak during emotional outbursts, to which we now refer as Baillarger-Jackson aphasia. It was 9 days after Baillarger's address that Broca, for the first time, unequivocally localized speech to the left frontal lobe.

This paper is based on the author's reading of Dax's and Broca's original texts and of the texts read before the Academy of Medicine meeting held at the National Library of France between April 4, 1865, and June 13, 1865. From these primary sources it is concluded that the Academy of Medicine's debate was the last serious challenge to left-hemisphere dominance for speech and to the localization of articulate language to the left frontal lobe-and that Jules Baillarger played a pivotal role in what was a defining moment in neurobiology.

https://thejns.org/doi/abs/10.3171/2019.6.FOCUS19256

KEYWORDS Jules Baillarger; Jean-Baptiste Bouillaud; Pierre Paul Broca; Broca's area; Marc Dax; language; speech

[We must] reject the idea that the faculty of articulate language resides in a fixed, circumscribed point.

$$
\text { - Pierre Paul Broca, } 1861^{16}
$$

The accepted view of the localization of articulate language-speech-to the posterior aspect of the third left frontal convolution is that it originated with Pierre Paul Broca's report of his first case of "aphemia" (aphasia) to the Society of Anthropology of Paris on April 18, 1861. ${ }^{17}$ Nothing could be further from the truth, as Broca initially proposed that both frontal lobes, in their entirety, were the seat of articulate language. That speech was localized to what is now referred to as Broca's area was accepted only after a bitter and abrasive debate held at the Imperial Academy of Medicine of Paris in the spring of 1865. Based on the author's reading of Marc Dax's and Broca's original texts, and the presentations made before the Academy of
Medicine from April 4 to June 13, 1865, this paper reviews the arguments that were made against the localization of speech and Jules Baillarger's critical role in overcoming them. It was Baillarger's support for the lateralization of speech to the left hemisphere that led Broca to finally acknowledge the localization of speech to the left frontal lobe, 4 years after his first report.

\section{The Localization of Speech Before Broca}

Franz Gall first proposed the localization of language to the frontal lobes in the first decades of the 19th century. Gall localized the "memory for words" and "spoken language" to the orbito-frontal regions of the brain, a proposition that was supported by Jean-Baptiste Bouillaud. Almost forgotten today, Bouillaud made numerous contributions to 


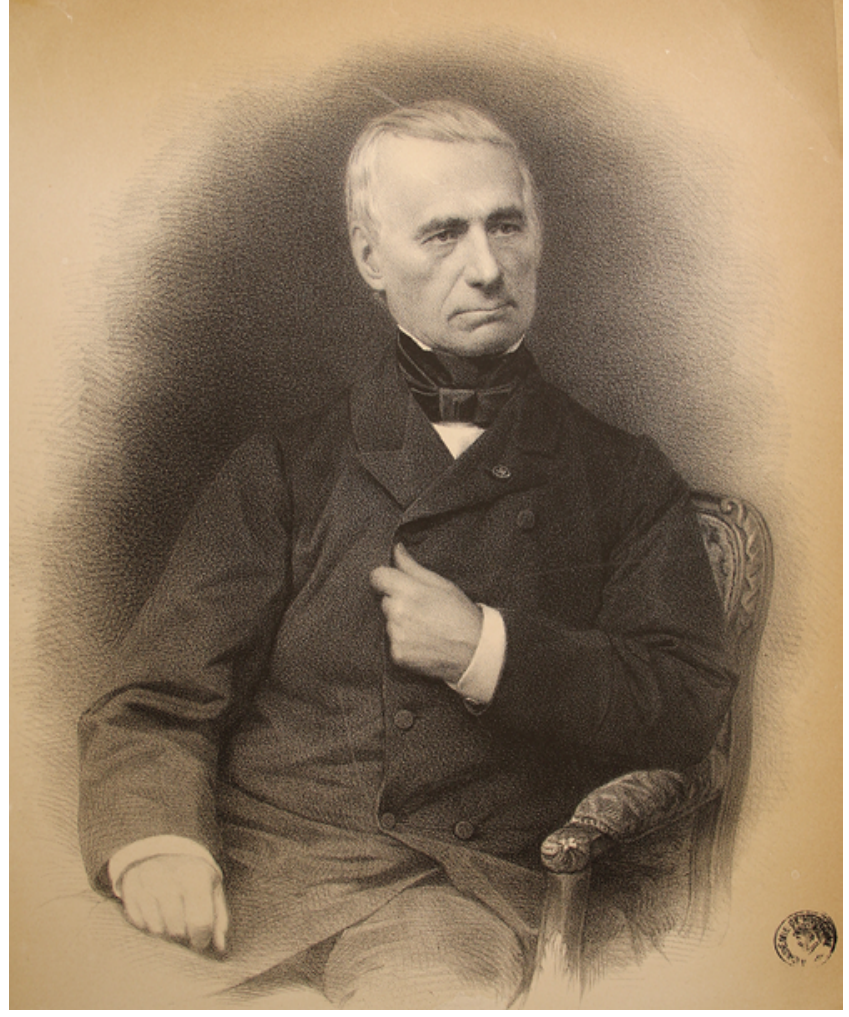

FIG. 1. Photograph of Jean-Baptiste Bouillaud (1796-1881). @ Bibliothèque de l'Académie nationale de médecine (Paris).

clinical medicine. He was the first to recognize the function of the cerebellum in coordinated movements, the first to describe pericarditis, and the first to describe the cardiovascular complications of rheumatic fever. ${ }^{9-12} \mathrm{He}$ was Dean of the Faculty of Medicine of Paris, President of the Academy of Medicine, and a distinguished member of the Academy of Sciences. ${ }^{33} \mathrm{He}$ was also a founding member and President of the Phrenological Society of Paris (Fig. 1).

Bouillaud, then aged 29, read a paper to the Academy of Medicine on February 21, 1825, with the long but descriptive title of "Clinical research demonstrating that loss of speech results from a lesion of the anterior lobules of the brain and confirming M. Gall's opinion on the seat of the organ of articulate language." 7 Bouillaud based his conclusion on his study of case reports of patients who had difficulty speaking and whose autopsies had revealed a lesion in the right, the left, or both frontal lobes. Bouillaud highlighted the case of an 81-year-old woman who had suffered an attack of apoplexy that left the movements of her limbs unaffected but rendered her unable to speak, which he felt was incontrovertible evidence of his theory:

Here is what the autopsy reveals: both anterior lobules of the brain in the portion nearest to the forehead are fused, softened; the whole of the lateral portion of the right lobule is in the same state.-Here we find a coincidence so striking, I would almost say palpable, between the loss of speech and the lesion of the anterior part of the brain, that this single observation would suffice to convince us to consider the first phenomenon as ... inseparable from the second.

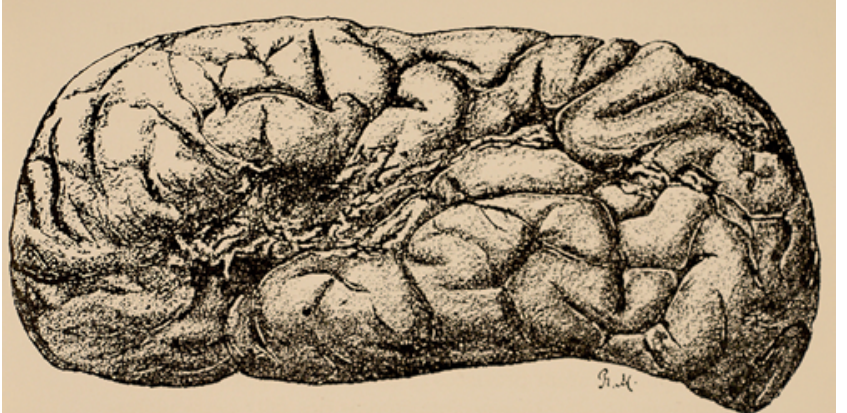

FIG. 2. Renée Moutier's drawing of Broca's first patient's left hemisphere, showing a lesion that Broca described as lying in "the mid-part of the frontal lobe of the left hemisphere." Renée Moutier was the wife of François Moutier, Pierre Marie's intern. The illustration appeared in F. Moutier: L'Aphasie de Broca. Paris: Steinheil, 1908. Public domain.

Bouillaud continued to accumulate cases throughout his career, all of which conformed to his theory. ${ }^{6,8}$

There the situation lay until April 4, 1861, when Bouillaud's-son-in-law, Ernest Auburtin, a distinguished physician in his own right, brought up the subject during a tumultuous meeting of the Society of Anthropology of Paris. Auburtin, in support of Bouillaud's position, told his audience that he had a patient under his care who was unable to speak, and in whom he expected to find a lesion in one or the other or both frontal lobes when the patient came to autopsy. Broca, who was in attendance, encountered a similar patient a few days later. At Broca's request, Auburtin examined this patient, and agreed that his case would be a suitable test of Bouillaud's theory. As it happened, Broca's patient came to autopsy before Auburtin's, and Broca reported his case.

Broca's patient had been unable to speak for some 20 years before he died of an infected phlegmon of his paralyzed right leg. Broca performed the autopsy on April 18,1861 , and reported his findings to the Society of Anthropology, his patient's freshly removed brain in hand, on the same day. ${ }^{17}$ The brain had a chronic lesion of the second and third left frontal convolutions, leading Broca to conclude that this had been the cause of his patient's loss of $\operatorname{speech}^{17}$ (Fig. 2). A complete report of this case was presented to the prestigious Anatomical Society the following August. He opened his address by stating, "The specimen and the report that I am submitting to the Société anatomique are in support of the ideas professed by Mr. Bouillaud on the seat of the faculty of language," and concluded with this affirmation, "Our observation therefore confirms Mr. Bouillaud's opinion that places the seat of articulate language in the [frontal] lobes."16 A few months later, Broca reported a second case of a patient who had lost the ability to speak, and who had a lesion at the same site as that of the first patient. ${ }^{16}$ Broca concluded this report by stating, "I am ... inclined to attribute the absolute similarity of the seat of the lesions in my two patients to pure coincidence [emphasis added]."16 Broca held the view that speech resides in both frontal lobes until the summer of 1865 .

On March 14, 1863, the Academy of Medicine received a copy of a paper that Marc Dax, a physician who 


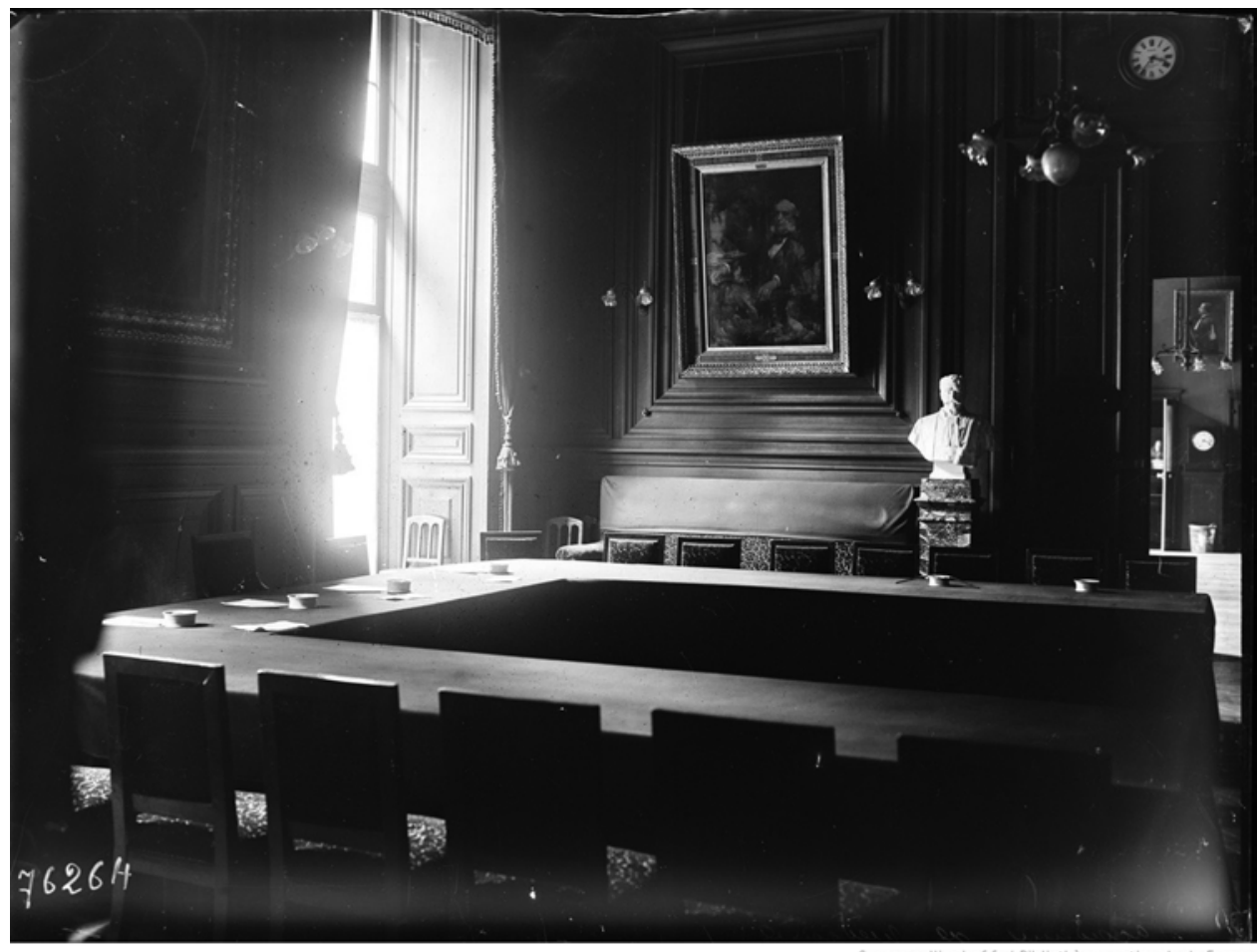

FIG. 3. Meeting room, Imperial Academy of Medicine. Courtesy of the Bibliothèque Nationale de France. Public domain.

had practiced in the south of France, had read before the French Southern Medical Congress of 1836. This paper stated that the ability to speak is the exclusive function of the left cerebral hemisphere. ${ }^{1,19}$ Marc Dax died the following year, and his report was forgotten until his son sent a copy to the Academy of Medicine. This body initiated a debate on the localization of speech that occupied it from April 4 to June 13, 1865 (Fig. 3).

\section{The Debate on Language Localization Jean-Baptiste Bouillaud}

Jean-Baptiste Bouillaud, now 69 years old, was the first to take the podium. ${ }^{5}$ Bouillaud took advantage of his time to expand upon his theory by suggesting that the intellectual aspects of speech reside in the cortices of both frontal lobes and that the centers coordinating the articulation of words reside within their subcortical white matter. Furthermore, he proposed that since the abilities to read and to write are often lost together with the loss of speech, these functions must also reside within the frontal lobes. Bouillaud, perhaps with some justification, credited Broca's discovery to his son-in-law, Auburtin. He considered Broca to have played but a secondary role. Perhaps in vindication of Auburtin, who had never reported the autopsy of his aphasic patient, Bouillaud concluded his address by displaying the freshly removed, unfixed brain of some unfortunate who had died unable to speak from a purulent lesion of a frontal lobe. Bouillaud's address had taken up three sessions of the Academy's time, in which he spoke over 40,000 words, and proved that he was "capable of the greatest feats of heroism, with the exception of being silent."23

\section{Armand Trousseau}

Armand Trousseau was the next to speak. Trousseau was Professor of Clinical Medicine at the University of Paris, the highest medical academic rank attainable in France $^{24}$ (Fig. 4). He enjoyed worldwide recognition for his discovery of the association of venous thrombosis and cancer (Trousseau's syndrome) and of carpal spasm as a sign of hypocalcemia (Trousseau's sign). ${ }^{34} \mathrm{He}$ also, much to Broca's displeasure, coined the word "aphasia" to replace Broca's own term of "aphemia," which he had used to describe his patient's inability to speak. ${ }^{35}$

Trousseau began by describing articulate language as "the manifestation of thought through words" and aphasia as "the inability to express that which we have the intention, the will to say." ${ }^{36}$ Trousseau then effortlessly drew from his own practice to identify the many elements that, singly or in combination, he considered to be part of the aphasic syndrome. These ranged from a complete loss of the ability to communicate a thought, either verbally, in writing, or with gestures, to examples of anomia, alexia, agraphia, and acalculia. These many manifestations of aphasia, Trousseau concluded, were too disparate to arise from a single location.

He then addressed the localization and lateralization of articulate language as proposed by Bouillaud, Broca, and Dax. In preparation for his address, Trousseau had reviewed 34 cases of aphasia that had been reported since the publication of Broca's first case and which had been carefully studied. Trousseau found that 18 patients had a lesion in a frontal lobe but that 16 did not, dealing a deathblow, he thought, to Bouillaud's and Broca's contention. 


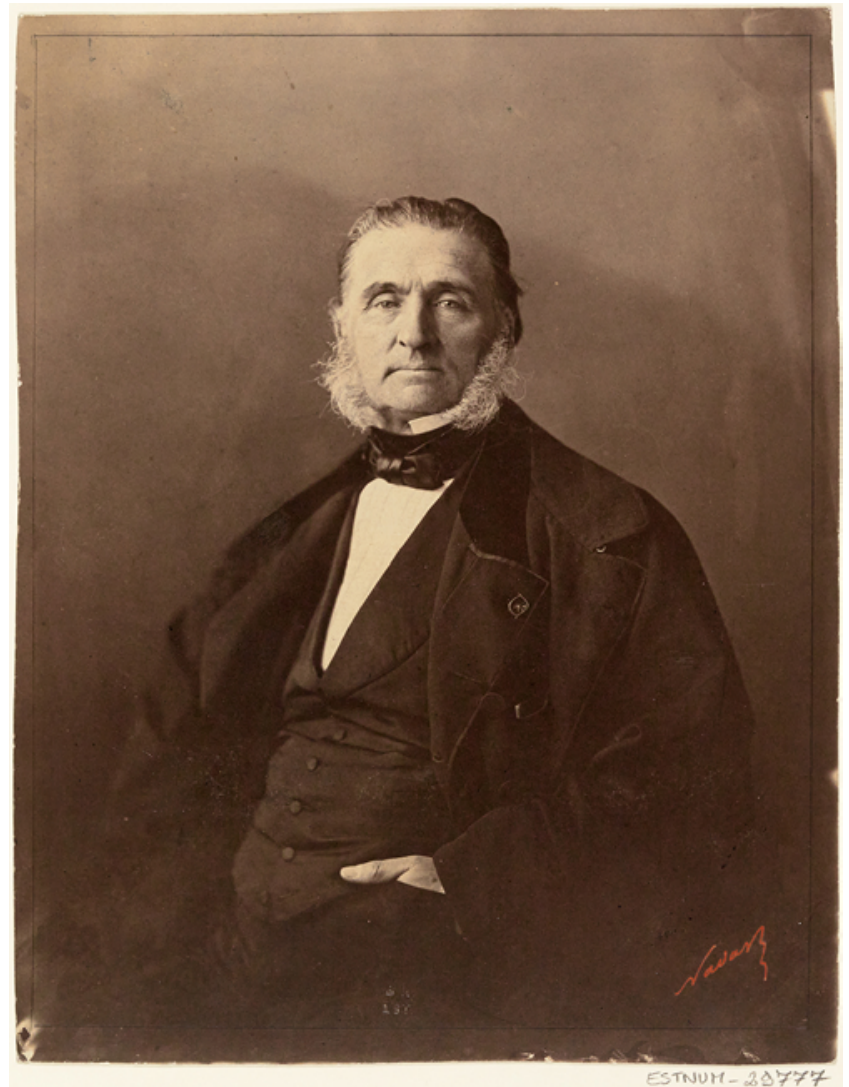

FIG. 4. Armand Trousseau (1801-1867). Photographer: Nadar (Gaspard Félix Tournachon). Courtesy of the Bibliothèque Nationale de France. Public domain.

Dax's paper was more problematic. Trousseau relied on Dax's own numbers, to which Trousseau added other cases that he judged to be informative, arriving at a total of 135 cases of aphasia, of which 125 (92\%) involved a lesion of the left hemisphere. Surprisingly, Trousseau was not convinced, and he stated, "In an organ as perfectly symmetrical as the brain, to say that one side subserves a function to the exclusion of the other, seems to me to belie common sense as well as physiology." Trousseau nonetheless proposed an anatomical peculiarity that could explain how the left hemisphere could meet the extra demands put upon it by language: "We could invoke in favor of M. Dax the special anatomic disposition of blood circulation to the brain, which is different on the right and on the left, where it arrives directly from the aorta through the common carotid artery, whereas on the right it come from the brachio-cephalic trunk." 36 Trousseau left the podium after this startling comment.

\section{Maximien Parchappe de Vinay}

Parchappe de Vinay is another physician whose contributions to medical science have largely been forgotten. Nonetheless, the insight that he displayed in his address to the Academy was stunningly prescient, considering the current emphasis on systems neurobiology. ${ }^{30}$

Parchappe de Vinay was a prominent psychiatrist who devoted his professional life to the care of patients suffer- ing from general paresis of the insane, a result of tertiary syphilis. ${ }^{29} \mathrm{He}$ was the first to recognize that the frontal cortex is the most significantly affected structure in this condition, which is characterized by alterations in language and loss of intellectual function. Thus, Parchappe considered language and intellect as inseparable. For him, language required the capacity to formulate thoughts, to translate these into words, and to string them into coherent, meaningful sentences. It also required the understanding of the meaning of words, the retention of their meaning, and the will to speak. Parchappe considered that will, ideation, memory, speech, and comprehension were integrated into the faculty of language and were called into action in speech. He further stated that the integration of these elements was assured by U-shaped fibers that join one convolution to another, by longer fiber tracts that join regions of the same hemisphere, and by the corpus callosum, connecting homologous regions of both hemispheres. "Thus," Parchappe concluded in his address, "would be reconciled, from pathology, anatomy, physiology and psychology, all the contradictions that sow confusion on the problem of the function of speech." This set the stage for the reconciliation of the localization of speech with the holistic function of language.

\section{Jules Baillarger}

I believe in the symmetry of function no less than in the anatomical symmetry of the brain.

- Pierre Paul Broca, $1865^{13}$

The reticence to accept left-hemisphere dominance for speech rested on one of the most resilient concepts of 19thcentury biology. Formulated by the great anatomist Xavier Bichat, it held that the tissue is the fundamental unit of biology and therefore, paired organs, such as the kidneys, the eyes, and the hemispheres of the brain, since they are constituted of the same tissue, have the same function. ${ }^{4}$ Bichat was quite explicit in this theory as it applied to the brain and nervous system:

Two perfectly similar globes receive light. Sounds and odors each also have their analogue double organs ... The nerves that transmit the impression received by the senses, such as the optic, the acoustic, the lingual, the olfactory, are evidently assembled as symmetrical pairs ... The brain, the organ where impression is received, is remarkable by its regular form; its paired parts resemble each other on either side ... The nerves that transmit the will of the brain to the agents of locomotion and of the voice: the locomotor organs formed in large part by the muscular system, of the skeletal system and its dependencies; the larynx and its accessories, [all] double agents of the executions of the will, have a regularity, a symmetry that are never betrayed ... We can thus conclude ... that symmetry is the essential characteristic of the organs of animal life of $\operatorname{man} .^{4}$

This is the reason why Bouillaud placed speech in both frontal lobes, and why Broca considered the occurrence of the lesion causing aphemia within the left frontal lobe of his patients to be a coincidence. This is also the paradigm that Jules Baillarger cast aside as he considered Dax's paper.

Baillarger was undoubtedly the most innovative speaker to address the Academy of Medicine, having discovered 


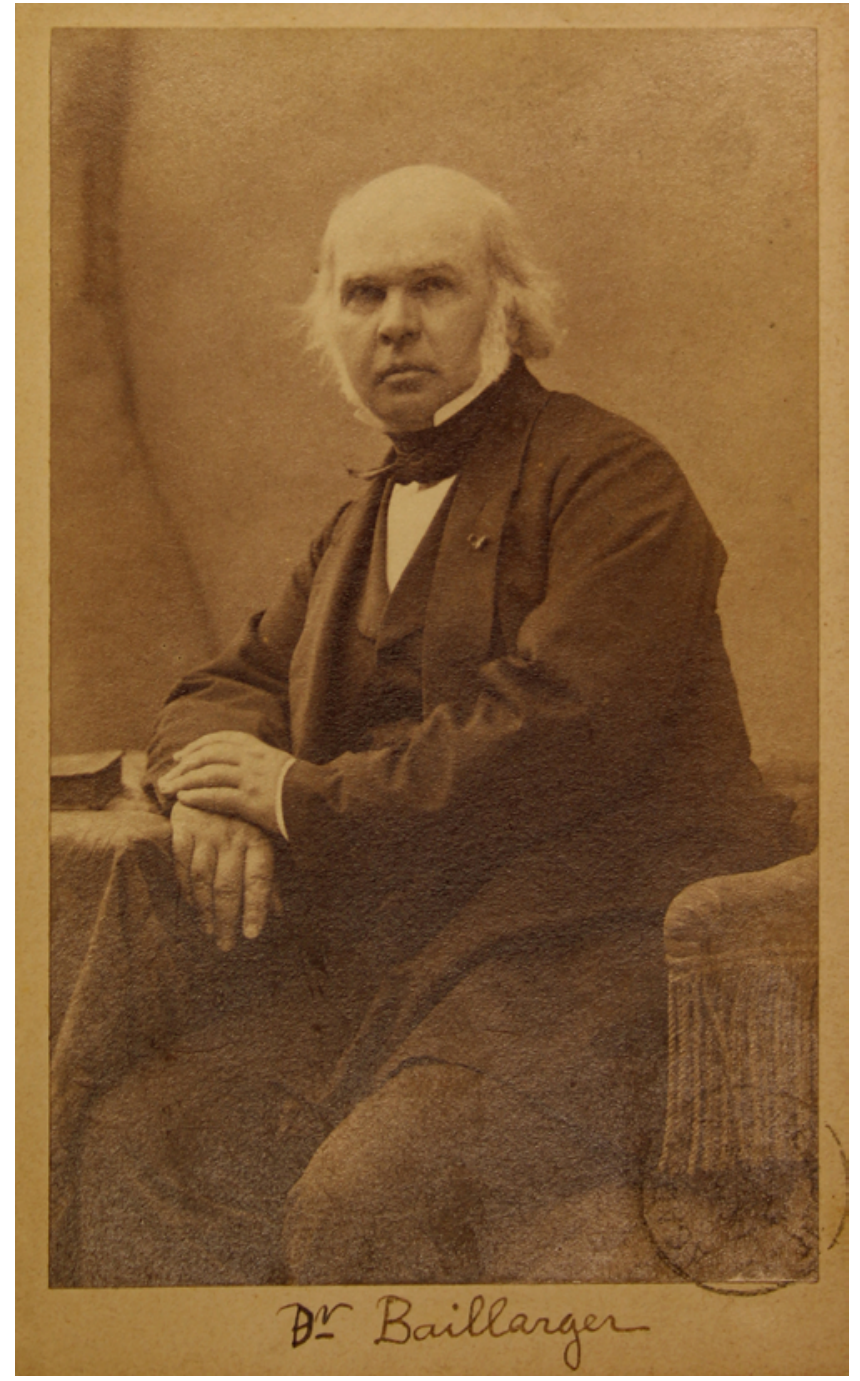

FIG. 5. Photograph of Jules Baillarger (1809-1890). @ Bibliothèque de l'Académie nationale de médecine (Paris).

the laminar structure of the cortex in $1840^{2}$ (Fig. 5). His address is a little-recognized landmark in aphasiology, as for the first time the dual nature of aphasia was described. Baillarger considered the inability to transmit thoughts through words, as described by Broca, as simple aphasia. He referred to the second form of aphasia, what is now call Wernicke's aphasia, as the perversion of the faculty of language:

There are many aphasics who have only lost, more or less completely, the ability to speak. This is simple aphasia, aphasia in the strict sense of the word. But besides these patients, there are others with a different affliction. They speak words that are unrelated to their thoughts. The lesion then constitutes a perversion of the faculty of articulate language. When this pervasion is severe ... it makes it impossible to express thought with words. The patient in whom dissociation between words and ideas has taken hold is as isolated from the external world as the one who is deprived of speech. ${ }^{3}$

Baillarger also related another aspect of aphasia, in which the aphasic retains the ability to utter intelligible words or fragments of sentences during an emotional outburst. This is now referred to as Baillarger's aphasia or as Baillarger-Jackson's aphasia.

In Baillarger's discussion of Dax's paper, he revealed that in a random survey of 31 recently reported aphasic cases all but one of the patients were paralyzed on the right side of the body. This was enough for Baillarger to declare Dax's discovery of left-hemisphere dominance for speech "a singular law." But, he continued, if Bichat's law of anatomical symmetry and unity of function did not apply to the hemispheres of the brain, how was it that the left one became the seat of language? He suggested two possible mechanisms. The first had already been raised: the left carotid artery's direct course from the arch of the aorta to the left hemisphere. Baillarger did not expand upon this, as his expertise lay in anatomy and not in the hydraulics of the cerebral circulation. And it is to anatomy that he looked for a second, more plausible explanation, based on the work of Louis-Pierre Gratiolet.

Gratiolet is best remembered for having been the first to recognize the organization of the brain into lobes, and for his discovery of the geniculo-calcarine tract. ${ }^{26} \mathrm{He}$ is less well remembered for having been the first to discover the asymmetry of the cerebral hemispheres, when he observed that the embryonic left frontal lobe enfolds earlier than the right. ${ }^{22}$ It was this fundamental difference that Baillarger invoked to explain the dominant role of the left hemisphere in language and of the "singular law" that Marc Dax had discovered:

Is it not absurd, it has been said, to maintain that the left
hemisphere is the only one responsible for speech? Is it
not as if we claimed that we see with only one eye, that we
hear with only one ear? In this regard I would remind you
that there are two anatomical facts in favor of the left hemi-
sphere that are of importance here. M. Trousseau has already
addressed the first of these, which relates to the circulation. It
is that the left common carotid artery originates directly from
the arch of the aorta, while on the right this same artery origi-
nates from the brachio-cephalic trunk. Gratiolet, the eminent
professor of whom science mourns the recent loss, has indi-
cated the second fact. "It has seemed to me" he said, "follow-
ing a series of conscientiously studied observations, that the
two hemispheres do not develop in a perfectly symmetrical
manner. Thus, the development of the frontal folds appears to
occur faster on the left than on the right." Let us accept that
Gratiolet's observation is correct, that the frontal convolutions
of the left hemisphere develop before those of the right, and
... the occurrence of aphasia, fifteen out of sixteen times in the
left hemisphere, would appear less strange.

As for Broca, Baillarger noted that there had been numerous credible case reports in which aphasia resulted from lesions of the left hemisphere that had not involved the frontal lobes. Thus Broca's localization of articulate language to the frontal lobes, unlike Dax's law, was for Baillarger only "relatively true."

Nine days after Baillarger's address, Broca (Fig. 6) read a paper to the Anthropological Society, in which, for the first time, he unequivocally localized articulate language to the left frontal lobe:

I reported ten cases of aphemia during the April 2 and 7, 1863 meetings in which lesions of the third frontal convolution 


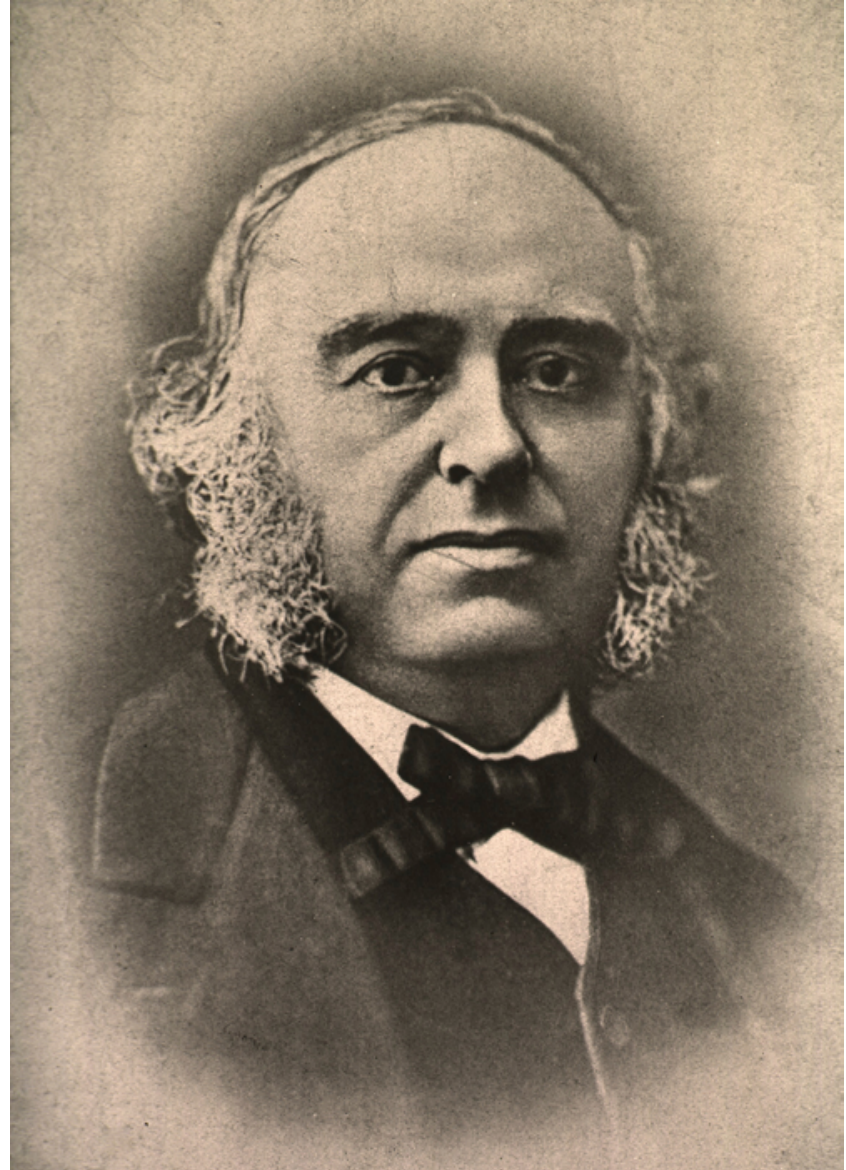

FIG. 6. Pierre Paul Broca (1824-1880). US National Library of Medicine. NLM Image ID No. B03577.

were found at autopsy. ... You will recall that in all of these cases the lesion was on the left, that I remarked upon this without concluding anything, and said that we had to await more cases before seeking an explanation for such a strange occurrence. ... Since then a large number of cases have been reported, in which almost all [the lesions have been on the left.] ... Recently, M. Baillarger reminded the Academy [of Medicine] that the convolutions of the left hemisphere precede those of the right as the brain develops. ... The earlier development of the left hemisphere predisposes us to perform the most complex intellectual acts with this half of the brain, including the expression of ideas through language, and more specifically, through articulate language. ${ }^{14}$

\section{Discussion}

The Academy of Medicine's debate was the last serious challenge to left-hemisphere dominance for speech and to the localization of articulate language to the left frontal lobe. Jules Baillarger played a critical role in both instances.

The resistance to the lateralization of language to the left hemisphere arose because it contradicted the prevailing paradigm of the unity of function of symmetrical organs. The reluctance to localize language to the frontal lobe was more complex. The most obvious reason is that

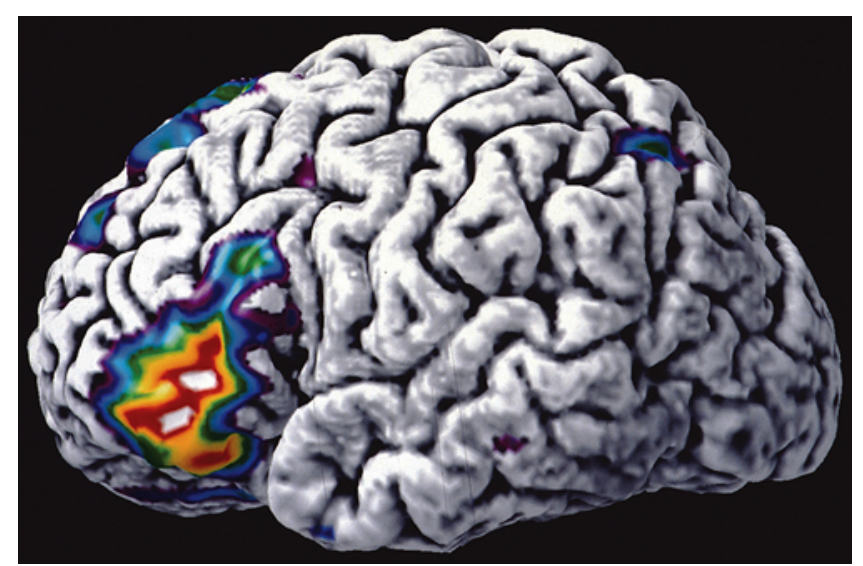

FIG. 7. Early functional activation of Broca's area. The image was obtained during a positron emission tomography scan while the subject was speaking. The data were integrated with the individual's MR image into a single data set, which is rendered as a 3D image. Courtesy of Dr. Denise Klein, Montreal Neurological Institute.

there were numerous reports of aphasic patients whose frontal lobes were found to be intact at autopsy. The question then arises as to why Bouillaud failed to find these cases in his studies. Simply put, the answer appears to be that he biased his results in order to support Gall's theory. ${ }^{27}$ Another reason for resistance to the localization of speech to a distinct area of the brain is that it smacked of phrenology, which had been discredited. A third reason was philosophical: the localization of an intellectual faculty unique to man, such as language, to a specific area of the brain was seen as supporting a materialistic, rather than a spiritual, interpretation of the human condition. ${ }^{18}$

Jules Baillarger disregarded these issues and relied on scientific detachment and his openness to new hypotheses based on evidence. Foremost among these was Gratiolet's finding of morphological differences between the cerebral hemispheres. A century later, hemispheric asymmetry was rediscovered by Brenda Milner and her group of researchers at the Montreal Neurological Institute ${ }^{28,32}$ and by Geschwind and Levitsky at Boston University. ${ }^{21}$

The suggestion that left-hemisphere dominance for speech was related to increased blood flow remained an open question. In 1877 this was submitted for review to a committee of the Academy of Medicine. Chaired by Bro$\mathrm{ca}$, this committee concluded that the direct course of the left carotid artery from the arch of the aorta could account for preferential flow to the left hemisphere. ${ }^{15}$ This led Broca to study differences in cerebral blood flow based on changes in temperature over defined vascular territory, in resting conditions and during functional activation of the brain, and in aphasic patients. ${ }^{25}$ Although his methodology was unreliable, Broca was the first to conceive that cerebral metabolism is related to cerebral blood flow, which is the basis of current functional imaging ${ }^{25}$ (Fig. 7).

Armand Trousseau thought that the numerous components of dysphasia were incompatible with a single localization, as Broca had proposed. In this, Trousseau was shown to be correct in 1874, when Karl Wernicke localized the receptive component of spoken language to the posterior 


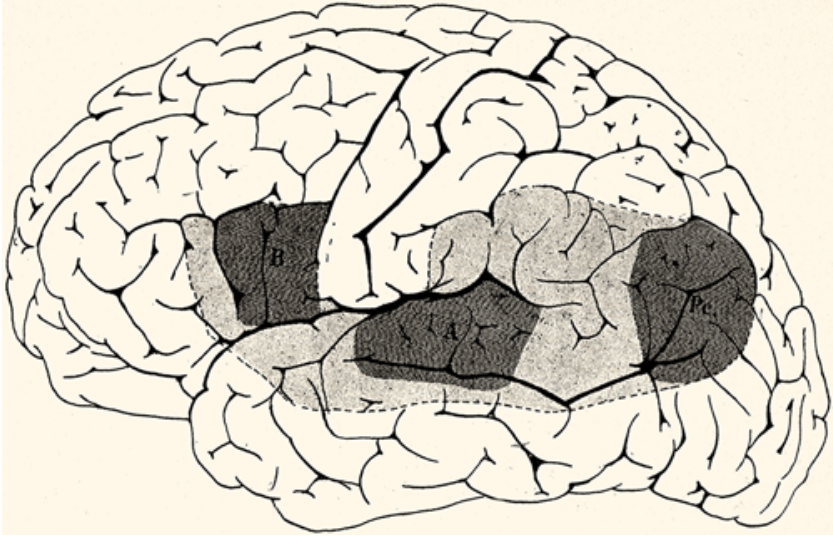

FIG. 8. Dejerine's language zone. $A$ indicates Wernicke's area. $B$ indicates Broca's area. Pc indicates "pli courbe"-the angular gyrus subserving written language. A lesion in any part of the shaded area, or of the subcortical fibers joining them, can affect all aspects of language, but the aspect most affected will be determined by the proximity to the function served by each darkly shaded area. Reproduced from Dejerine J, Dejerine-Klumpke A: Anatomie des centres nerveux, vol. 2. Paris: Rueff, 1901. Public domain.

aspects of the first and second left temporal convolutions, and in 1891, when Jules Dejerine localized the receptive and expressive aspects of written language to the left inferior parietal lobule. Dejerine went further by uniting these areas into a "zone de langage"-a language zone-that encircles the left sylvian fissure. ${ }^{20}$ Dejerine's language zone is anchored anteriorly by Broca's area, posteriorly by the inferior parietal lobule, and inferiorly by Wernicke's area, all of which are linked by subcortical white-matter fibers. In this, Dejerine owes much to Parchappe de Vinay, who postulated the existence of such fibers, and to his wife, $\mathrm{Au}-$ gusta Dejerine-Klumpke, who demonstrated the connection of Wernicke's and Broca's areas through the arcuate fasciculus. ${ }^{20}$ As Dejerine conceptualized the function of the language region, "any alteration of the language zone at any point in the surface that it occupies does not result in difficulties limited to this or that modality of language, but an alteration in all modalities of language, with predominance of those difficulties corresponding to the ... center directly affected by the lesion"20 (Fig. 8).

The localization of eloquent areas to specific sites had depended on the application of the clinicopathological method-lesion analysis - which is based on correlating a specific symptom or sign within a spectrum of deficits, to a discrete area of a diffusely damaged brain, as might be present in a middle cerebral artery stroke. Direct confirmation of the results obtained by Broca, Wernicke, and Dejerine, and the discovery of the language function of the supplementary motor area, was achieved by the work of Wilder Penfield and Lamar Roberts using cortical stimulation in awake patients, published in 1959 in Speech and Brain Mechanisms. ${ }^{31}$ Echoing Parchappe and Dejerine, Penfield concluded Speech and Brain Mechanisms by stating, "The first sure evidence ... to distinguish functional units within the brain appeared ... with the discovery of a speech mechanism within one hemisphere. ... Now that we can recognize the parts of the dominant cortex and thala- mus that are devoted to the learning of speech and to its uses, we must seek constructive hypotheses which fit the function of speech into the total functioning of the brain." This task is still before us.

\section{Acknowledgments}

The Thomas Willis Fund and the Neuro History Project of the Montreal Neurological Institute supported this work. I am grateful to Dr. Kathleen F. Knowles for help with copyediting.

\section{References}

1. Anonymous: Observations tendant à prouver la coïncidence constante des dérangements de la parole, avec une lésion de l'hémisphère gauche du cerveau, par M. le docteur Dax. Bull Acad Imp Med 28:497, 1863

2. Baillarger J: Recherches sur la couche corticale des circonvolutions du cerveau. Mém Acad Roy Med 8:149-183, 1840

3. Baillarger J: Sur la faculté du langage articulé. Bull Acad Med 30:816-832, 1865

4. Bichat FX: Recherches physiologiques sur la vie et la mort. Paris: Béchet Jeune et Gabon, 1822

5. Bouillaud JB: Discussion sur la faculté du langage articulé. Bull Acad Med 30:575-600, 1865

6. Bouillaud JB: Exposition de nouveaux faits à l'appui de l'opinion qui localise dans les lobules antérieurs du cerveau le principe législateur de la parole examens préliminaires des objections dont cette opinion a été' le sujet. Bull Acad Roy Med 4:282-328, 1839

7. Bouillaud JB: Recherches cliniques propres a démontrer que la perte de la parole correspond à la lésion des lobules antérieurs du cerveau et à confirmer l'opinion de $\mathrm{M}$. Gall, sur le siège de l'organe du langage articulé. Arch Gen Med 8:284, 1825

8. Bouillaud JB: Recherches cliniques propres à démontrer que le sens du langage articulé est le principe coordinateur des mouvements de la parole résident dans les lobules antérieurs du cerveau. Bull Acad Roy Med 13:699-719, 1848

9. Bouillaud JB: Traité clinique et physiologique de l'encéphalite ou inflammation du cerveau et de ses suites. Paris: JB Baillière, 1825

10. Bouillaud JB: Traité clinique de rhumatisme articulaire et de la loi de coïncidence des inflammations du coeur avec cette maladie. Paris: JB Baillière, 1840

11. Bouillaud JB: Traité clinique des maladies du coeur: précédé de recherches nouvelles sur l'anatomie et la physiologie de cet organe. Paris: JB Baillière, 1835

12. Bouillaud JB: Recherches cliniques tendant à réfuter l'opinion de M. Gall sur les fonctions du cervelet, et a prouver que cet organe préside aux actes de l'équilibration, de la station et de la progression. Arch Gen Med 15:225-247, 1827

13. Broca P: Discussion sur l'aphémie. Bull Soc Anthropo 6:412-417, 1865

14. Broca P: Du siège de la faculté du langage articulé. Bull Soc Anthropo 6:377-393, 1865

15. Broca P: Rapports. Bull Acad Med Série 2 6:508-530, 1877

16. Broca P: Remarques sur le siege de la faculté du langage articulé suivies d'une observation d'aphémie. Bull Soc Anato 6:330-357, 1861

17. Broca P: Siège de la faculté du langage articulé. Perte de la parole. Ramollissement chronique et destruction partielle du lobe antérieure gauche du cerveau. Bull Soc Anthropo 2:235, 1861

18. Clarke E, Jacyna LS: Nineteenth-Century Origins of Neuroscientific Concepts. Oakland, CA: University of California Press, 1992

19. Dax M: Lésions de la moitié gauche de l'encéphale coïncidant avec l'oubli des signes de la pensée. Gaz Heb Med Chir 2:259-260, 1865 
20. Dejerine J, Dejerine-Klumpke A: Anatomie des centres nerveux. Paris: Rueff, 1901, Vol 2, pp 247-248, 756-758

21. Geschwind N, Levitsky W: Human brain: left-right asymmetries in temporal speech region. Science 161:186-187, 1968

22. Gratiolet P: Mémoire sur les plis cérébraux de l'homme et des primates. Paris: Bertrand, 1854

23. Jacquemet: Rapport sur l'inégalité fonctionnelle des deux hémisphères cérébraux: MM. Broca, de Fleury, Bouillaud, Dax. Montpellier Médicale 6:559-568, 1877

24. Labarthe P: Nos médecins contemporains. Paris: LebigreDuquesne, 1868, pp 65-75

25. Leblanc R: Beyond descriptive neurology: Broca, cerebral hemodynamics, and cortical function. J Hist Neurosci 27:36-55, 2018

26. Leuret F, Gratiolet P: Anatomie comparée du système nerveux considéré dans ses rapports avec l'intelligence. Paris: JB Baillière, 1839, Vol 1

27. Luzzatti C, Whitaker H: Jean-Baptiste Bouillaud, ClaudeFrançois Lallemand, and the role of the frontal lobe: location and mislocation of language in the early 19th century. Arch Neurol 58:1157-1162, 2001

28. McRae DL, Branch CL, Milner B: The occipital horns and cerebral dominance. Neurology 18:95-98, 1968

29. Parchappe JB: Recherches sur l'encéphale, sa structure, ses fonctions et ses maladies. Paris: JB Baillière, 1862, Vol 1, pp 141-176

30. Parchappe JB: Sur la faculté du langage articulé. Bull Acad Med 30:679-703, 1865
31. Penfield W, Roberts L: Speech and Brain Mechanisms. Princeton, NJ: Princeton University Press, 1959

32. Ratcliff G, Dila C, Taylor L, Milner B: The morphological asymmetry of the hemispheres and cerebral dominance for speech: a possible relationship. Brain Lang 11:87-98, 1980

33. Rolleston JD: Jean Baptiste Bouillaud (1796-1881). A pioneer in cardiology and neurology. Proc R Soc Med 24:12531262,1931

34. Trousseau A: Clinique médicale de l'Hôtel-Dieu de Paris. Paris: JB Baillière, 1865

35. Trousseau A: De l'aphasie, maladie d'écrite récemment sous le nom impropre d'aphémie. Gazette des Hôpitaux Civils et Militaires (Lancette Française) 37:13-14, 25-26, 37-39, 49-50, 1864

36. Trousseau A: Sur la faculté du langage articulé. Bull Acad Med 30:647-656, 1865

\section{Disclosures}

The author reports no conflict of interest concerning the materials or methods used in this study or the findings specified in this paper.

\section{Correspondence}

Richard Leblanc: Montreal Neurological Institute and McGill University, Montreal, QC, Canada.richard.leblanc@mcgill.ca. 